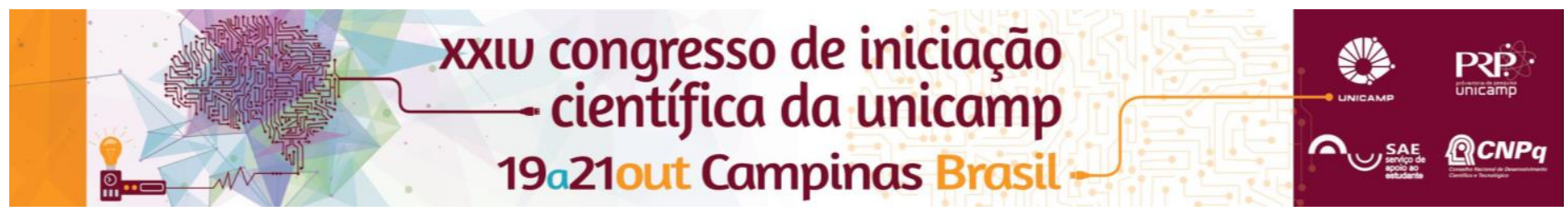

\title{
Vulnerabilidade em Limeira - SP - o fator renda e a segregação espacial da população.
}

\author{
Aline Ferreira (Bolsista PIBIC/CNPq) * \\ Álvaro de Oliveira D' Antona (Orientador) *
}

\section{Resumo}

O trabalho mapeia as áreas de vulnerabilidade socioeconômica no município de Limeira, no estado de São Paulo, com o propósito de relacionar espacialmente a vulnerabilidade da população com outros indicadores da ocupação da mancha urbana e com a renda dos moradores. Trabalhando com setores censitários como unidades territoriais de análise, buscou-se verificar como se dá a ocupação nas áreas de maior vulnerabilidade, aquelas expostas a condições habitacionais mais precárias. O IPVS 2010 foi utilizado como medida da vulnerabilidade; o IPTU, como uma proxy das condições/tipo de moradia e de ocupação. Variáveis sociodemográficas do Censo 2010 (renda) foram incorporadas aos testes. Os resultados indicam correlação entre renda, IPVS e valor do IPTU, essas análises estatísticas comprovam que as regiões onde a renda é mais baixa o valor do imóvel é mais barato e consequentemente a vulnerabilidade social é maior. Tal resultado é compatível com um quadro de urbanização segregadora, no qual as porções mais precárias são aquelas ocupadas pelas camadas de população com mais baixa renda.

\section{Palavras-chave:}

Áreas de risco, Fator renda, segregação espacial.

\section{Introdução}

Segundo Torres e Gonçalves (2007), o mercado imobiliário ao ofertar uma reduzida quantidade de terras atrelada ao alto preço do solo urbano contribuem para que uma parcela expressiva da população é forçada a morar em regiões desvalorizadas pelo setor de imóveis.

A concepção de Vulnerabilidade incorpora além das populações em risco, mas sua capacidade de reagir as situações adversas. Nos permitindo incorporar mais mecanismo além dos materiais para a constatação de famílias em situação de risco. (HOGAN et al., 2010 apud MARANDOLA JR; D'ANTONA, 2012).

Diante disso foram feitas análises estatísticas para verificar a correlação entre as variáveis Renda, IPTU e IPVS. Conseguindo concluir ao final do trabalho e verificar a tese inicial, mostrando a correlação entre as variáveis e localizando espacialmente a segregação imobiliária de acordo com a renda dos munícipes.

\section{Resultados e Discussão}

A composição empírica do trabalho fez o tratamento dos dados com atributos estatísticos de correlação. As variáveis: Renda, IPVS e IPTU, foram comparadas entre si para medirmos o grau de sua veracidade com a realidade. Chegando a valores entre 1 e -1 , onde a sua maior proximidade com o 0 , permite a sua maior veracidade com a realidade empírica do município. A tabela a seguir mostra os resultados através da correlação feitos pelo Excel:

Tabela 1. Correlação das variáveis: Renda, IPVS e IPTU.

\begin{tabular}{|l|c|c|c|}
\hline & Renda & IPVS & IPTU \\
\hline Renda & - & $-0,229441927$ & $-0,034009472$ \\
\hline IPVS & $-0,2294419272$ & - & $-0,013075084$ \\
\hline IPTU & $-0,034009472$ & $-0,013075084$ & - \\
\hline \multicolumn{3}{|c|}{ Fonte: Autoria dos autores }
\end{tabular}

E o mapa abaixo mostra espacialmente a maneira que os dados da tabela comprovam-se geograficamente no município de Limeira -

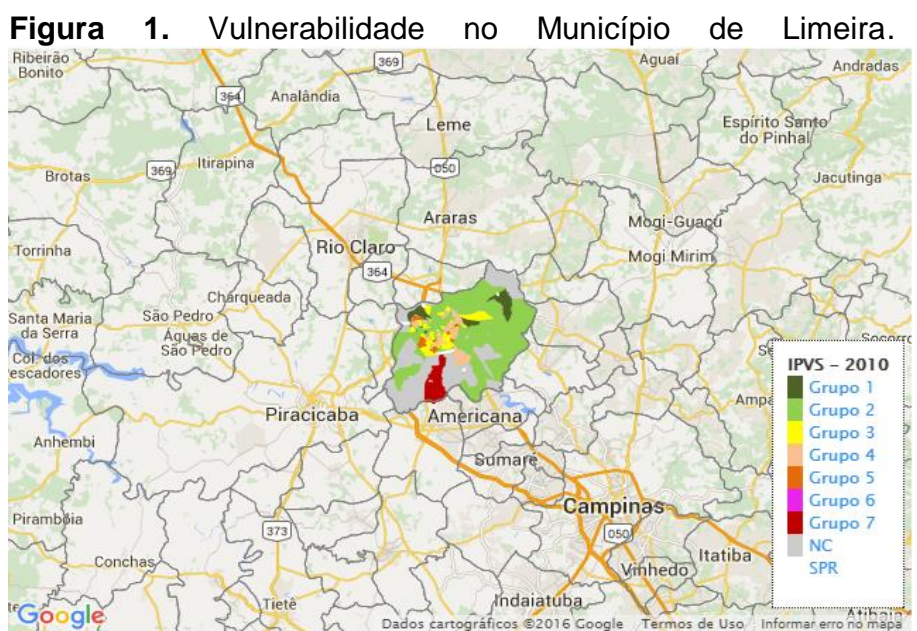

Fonte: Assembleia Legislativa do Estado de São Paulo (Adaptado)

\section{Conclusões}

Em suma, é possível verificar que as hipóteses feitas no começo do trabalham comprovam empiricamente com as definições conceituais. As populações de renda mais baixa, localizam em regiões com maior vulnerabilidade social e onde o valor do imóvel é mais baixo. Sendo assim conseguimos verificar a relação do fator renda ser responsável por restringir o acesso a localidades de maior infraestrutura e preço da terra.

\section{Agradecimentos

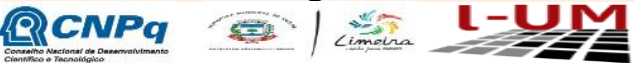

TORRES, H, G; GONÇALVES, R. O mercado de terras em São Paulo. E a contínua expansão da periferia. Revista Brasileira de Estudos Urbanos e Regionais, v.9, n.2/ Novembro de 2007.

MARANDOLA, JR; D'ANTONA, A. Vulnerabilidade: Problematizando e Operacionalizando o Conceito. In: Contexto do Projeto GERMA - "Geografia dos riscos e mudanças ambientais: construção de metodologias para o estudo da vulnerabilidade". (FAPESP n.2012/1008-02), do Laboratório de Geografia dos Riscos e Resiliência (LAGERR/ CHS/ FCA/ Unicamp).

Assembleia Legislativa do Estado de São Paulo. Vulnerabilidade no município de Limeira. Disponível em: < http://indices-ilp.al.sp.gov.br/view/index.php $>$. Acesso em 10/07/2016. 